\title{
As intermitências da filosofia no ensino básico: um quadro histórico-crítico
}

\author{
The intermittency of philosophy in basic education: a brief historical critical
}

DIAS-SANTOS, André Ricardo. Doutor/Licenciado em Filosofia

Instituto Federal de Educação, Ciência e Tecnologia do Sertão Pernambucano - Campus Petrolina. Rua Maria Luiza de Araújo Gomes Cabral, S/N, João de Deus - Petrolina - Pernambuco - Brasil. CEP: 56.316-686 /

Telefone: (87) 2101-4300 / E-mail: andre.dias@ifsertao-pe.edu.br

\section{RESUMO}

No presente artigo, traçamos um breve histórico das inserções da disciplina Filosofia, a qual se faz presente na grade curricular do ensino básico no Brasil, desde a década de 1960. Este histórico se relaciona de maneira crítica à exposição do estatuto atual da Filosofia, enquanto componente curricular no contexto das últimas reformas da educação, no tocante aos princípios e diretrizes gerais norteadores do ensino básico, no Brasil. Nossa intenção é apresentar estas políticas de Estado para o campo educacional pela exposição de tais "contrarreformas", compreendidas como forma de esvaziamento curricular, empobrecimento da formação humana e de seus conhecimentos em nome da financeirização da educação no país.

Palavras-chave: Ensino; Filosofia; Reformas educacionais.

\begin{abstract}
In this article we trace a brief history concerns insertions on Philosophy in the basic educational curriculum of Brazil, since the 1960 s to the present day. This history is critically related to a exposure of current philosophy status as a curricular component in the latest educational reforms context, with special regard to its general principles and guidelines that forms basic education. We intend to present how these State policies for educational area tend to evidence such a "counter-reforms", taking place as a mean of curricular emptying, impoverishment of human formation and subsequent knowledge, under the intention of financializing education in the country.
\end{abstract}

Keywords: teaching, philosophy, educational reforms.

\section{Introdução}

A curtíssima história da filosofia no ensino básico no Brasil data do início da tardia escolarização moderna, mas, em nosso escopo, trataremos de suas inserções e supressões no ensino da metade do século XX até os dias atuais. Este recorte histórico conforma uma interpretação política deste movimento, que perpassa pelos períodos institucionais do Estado brasileiro, gerenciado por governos democráticos ou ditatoriais. Neste quadro, os princípios e os pressupostos teóricometodológicos do currículo escolar seguem o humor político e econômico da ordem que são determinados pelas decisões burocráticas do Estado, como vemos na atualidade com o advento do 
DIAS-SANTOS, A. R. (2020)

As intermitências da filosofia no ensino básico: um quadro histórico-crítico

"novo ensino médio".".

Além dos problemas relativos às políticas de Estado para a educação, há que se considerar as lacunas teóricas do campo de pesquisa da Filosofia acadêmica, dos quais nos aproximamos da reflexão sobre o estatuto da Filosofia enquanto disciplina escolar. Lembramos aqui as críticas do aparelho escolar, com Bourdieu e Passeron (1970), em que a escola realiza uma função de disciplinamento para uma razão social de natureza mercantil nas sociedades modernas, tal qual em Foucault (2007) e Marcuse (2006), com os quais também podemos alargar uma crítica tardia à disciplina the atribuindo a função principal de manutenção da própria escola, este "aparelho de dominação" de corpos e mentes. Neste sentido, resta uma crítica à noção de formação, quando a escola não teria por razão precípua exatamente a formação do educando, mas a manutenção de um estado de dominação e de controle por parte do Estado e dos blocos de poder que alternadamente o gerem.

Compreendemos o estudo da Filosofia, dentro de uma matriz curricular, como um espaço de trabalho para o conhecimento filosófico que pode transcender os limites do conceito de componente curricular. Neste sentido, valemos da possibilidade de elaboração de pensamento e produção da crítica textual, a partir das ideias e da análise teorética que nos oferece a história da Filosofia. Frente a este caráter criador e vivo da crítica, regimes políticos como as ditaduras militares se mantiveram hostis à presença de disciplinas como a Filosofia e a Sociologia, além de manterem a tendência de controle sobre as demais disciplinas, seus conteúdos e imporem o controle ideológico sobre o exercício da docência.

É neste contexto histórico e político que apresentaremos os revezes da disciplina da Filosofia nas escolas do Brasil. Para este exercício, contudo, faz-se indispensável a exposição das últimas mudanças das legislações e diretrizes para a educação escolar implantadas nas últimas décadas. Este panorama remete a um quadro histórico que compreende mais de meio século de história social do Brasil. Pela via da interpretação histórica e crítica, este percurso revela não apenas a pequena história da Filosofia em nossas escolas, mas, sobretudo, a história da política educacional e seus meandros na deriva de governos e orientações ideológicas do momento.

\section{Histórico da disciplina Filosofia desde a década de 1960}

A última grande reforma da educação no Brasil foi expressa na lei n. 9.394/1996, ao instituir as novas diretrizes e bases para o ensino em geral. No ensino básico, a Lei de Diretrizes e Bases da educação nacional precípua uma temporalidade mínima de três anos para o total de períodos letivos, compreendendo disciplinas e conteúdos obrigatórios, unidade temática entre os sistemas de ensino, em nome de uma isonomia entre Estados federados e sistemas locais de ensino, além de democratizar uma base curricular única para todo o país. Nestes termos, ficou definido pela LDB:

1 O chamado "novo ensino médio" foi implementado através da medida provisória n. 746/2016 e consolidado na lei n. 13.415/2017. A seguir, trataremos de seu histórico e das alterações na LDB/96 decorrentes de sua efetivação. 
As intermitências da filosofia no ensino básico: um quadro histórico-crítico

A lei n. 9.394/1996 definiu que o ensino médio deveria ser realizado com no mínimo três anos (600 dias e 2.400 horas - 25\% parte diversificada e $75 \%$ de base nacional comum). Com uma série de disciplinas e componentes curriculares obrigatórios, o ensino médio reúne extenso conjunto de conteúdos que deve consolidar o ensino fundamental e permitir o prosseguimento dos estudos no ensino superior. Essa etapa de ensino, quando integrada à educação profissional técnica de nível médio, pode chegar a quatro anos em horário parcial e ou em três anos em horário integral, totalizando uma carga horária que pode oscilar entre três mil e quatro mil horas - dependendo da área profissional a ser definida no catálogo nacional de cursos. Além disso, o ensino médio, em seu transcurso, deve permitir transferências entre sistemas e unidades de ensino e, em sua conclusão, propiciar aos educandos a apropriação dos fundamentos científicos e tecnológicos da produção moderna (BRASIL, 1996, apud Lima, 2018, p. 09)

No contexto da LDB, a disciplina de Filosofia é reinserida no currículo após vinte e cinco anos de ausência na grade curricular do ensino básico, período compreendido pelos governos militares, decorrentes da ditadura militar, regime político que assolou sobremaneira a educação no país. Vejamos um histórico da disciplina em um retorno ao início desta cronologia.

Em 1961, a Lei n. 4.024/61 retira a obrigatoriedade da oferta da nossa disciplina dos currículos escolares ${ }^{2}$. A lei expressa a política desenvolvimentista dos anos do governo de Juscelino Kubitschek e compreende a fixação das Diretrizes e Bases da educação nacional, garantindo o acesso universal à educação e significando uma reformulação dos currículos. Esta modernização segue sob orientações de natureza profissionalizante e por uma forte ideia de cientificidade, com ênfase no estabelecimento das chamadas "disciplinas científicas" do campo das ciências exatas e da natureza. Já nos primeiros anos da ditadura militar brasileira (1964-1985), sob a gestão de Médici (1968-1974), a filosofia sai definitivamente dos currículos pelas alterações trazidas ao texto da Lei das Diretrizes e Bases pela nova Lei 5.692/71 Esta última aprofunda a orientação profissionalizante na educação, desta vez instituindo o ensino profissional obrigatório ${ }^{3}$.

Após quase uma década de redemocratização, as discussões acerca de uma mudança nas Leis de Diretrizes e Bases, iniciadas no período pós constituinte (1988), ganham corpo normativo com a proposta da Lei n. 9.394/96, a nova LDB, sendo necessários mais três anos para que as decisões estabelecidas pela LDB fossem condensadas em legislações específicas e canalizadas para as diversas modalidades de ensino. Foi assim com as Diretrizes Curriculares para o Ensino Médio, com a Resolução CEB/CNE ${ }^{4}$ n.03 de 26 de junho de 1998 e os PCNEM (Parâmetros Curriculares Nacionais para o Ensino Médio) de 1999/2000. Nestes documentos, a disciplina de Filosofia é reescrita nos currículos, dando corpo às disposições prescritas pela LDB de 1996, na qual a determinação legal prevê o acesso dos

\footnotetext{
2 “Em 1961, no apagar das luzes do governo de Juscelino Kubitschek, com a lei n. 4.024/61, a filosofia deixa de ser obrigatória nos currículos escolares, status conquistado desde o período de D. João VI” (MOREIRA, 2018, p. 243).

3 “Os discursos em torno da Lei 5.692/71, durante a ditadura militar brasileira, e que substituíram praticamente na íntegra a legislação educacional expressa pela primeira Lei de Diretrizes e Bases da Educação, a Lei 4.024/61, diziam que a necessidade de alteração da legislação atendia aos ditames de um "novo" momento social. Para tanto, esse momento pedia uma "nova" escola e uma "nova" visão educacional. Assim, a Lei 5.692/71 foi saudada como a panaceia, como a redenção da educação brasileira, ironicamente, até mesmo entre os educadores no período militar. A reforma educacional implantada atendia ao chamado de construção de um "projeto nacional" que serviria como alavanca para o desenvolvimento do "Brasil - Potência” (Jacomeli, 2010, p.77).

4 Câmara de Educação Básica do Conselho Nacional de Educação.
} 
educandos aos saberes e conteúdos didáticos da Filosofia até o final do ensino médio. ${ }^{5}$ (Fávero, p.259, 2004).

Para contemplar esta previsão, ficou estabelecida, nos PCNEM, a disposição dos conhecimentos em Filosofia e Sociologia no eixo temático dos chamados Temas Transversais, componente curricular da área das Ciências Humanas e Suas Tecnologias, da Base Nacional Comum (BNC). Como se vê, isso significou realocar as duas áreas na grade curricular não como disciplinas independentes e autônomas, embora tal configuração coubesse na interpretação das disposições da LDB/96. As razões para esta condensação podem perpassar questões econômicas e políticas as quais, por fim, orientam as disposições dos conselhos e das câmaras, ao sabor do poder vigente:

Os Parâmetros Curriculares Nacionais para o Ensino Fundamental (PCNEF), publicados em 1998, preveem a adoção de temas transversais nesse nível de ensino, notadamente nas áreas de ética e cidadania. Também os Parâmetros Curriculares Nacionais para o Ensino Médio (PCNEM), de 1999, preveem que conteúdos de filosofia devam ser trabalhados na forma de temas transversais, embora, nestes, a filosofia apareça como uma disciplina da área de "Ciências Humanas e Suas Tecnologias". Estas disposições especificam o que já a LDB havia determinado (Seção IV, artigo 36, parágrafo $1^{\circ}$ ): que os estudantes, ao final do ensino médio, demonstrem "dominar os conhecimentos de filosofia e de sociologia necessários ao exercício da cidadania (FÁVERO, 2004, p. 267).

Da prática curricular dos Temas Transversais resta difícil o estabelecimento de uma avaliação da efetividade de uma prática filosófica, diluída na abordagem de temáticas "gerais", características dos discursos transversais, marcados por uma urgência ideológica expressa nas mesmas disposições legais que o implantaram como disciplina, vinculando-o ao estudo da cidadania. Quanto à Filosofia, a vinculação legal de seus saberes à grade curricular se deu por uma razão instrumental, o que deveria levar o estudante ao "domínio dos conhecimentos de Filosofia e de Sociologia necessários ao exercício da cidadania". Esta orientação restringe o campo do saber a algo próximo à vertente da Filosofia Prática, comumente compreendida pelos estudos em Ética e Política. Porém, depreende-se das experiências em sala de aula daqueles anos em que o trabalho destes temas se deu fortemente orientado por autores e concepções ligados à ideologia de Estado, de orientação teórica liberal ou, nos estertores do neoliberalismo em fins dos anos 90 , sob aguda orientação ideológica da economia de livre-mercado. Quando encontramos relatos de experiências avessas a estas ideologias, estamos em terreno da crítica marxista, ou do trabalho crítico do materialismo histórico-dialético. De todo modo, a polaridade ideológica, a despeito, aqui, do julgamento crítico de tais filiações, demonstram os limites patentes que circundavam a volta da Filosofia dentro daqueles moldes. Isto quando, entretanto, se tratava de trazer algo da Filosofia para a sala de aula. No pior dos cenários, sequer a palavra Filosofia chega a ser pronunciada.

Alguns anos depois, o tema do ensino obrigatório da Filosofia e da Sociologia voltou a ser

\footnotetext{
5 “Art. 36, § $1^{\circ}$. "Os conteúdos, as metodologias e as formas de avaliação serão organizados de tal forma que ao final do ensino médio o educando demonstre: I - domínio dos princípios científicos e tecnológicos que presidem a produção moderna; II - conhecimento das formas contemporâneas de linguagem; III - domínio dos conhecimentos de Filosofia e de Sociologia necessários ao exercício da cidadania" Disponível em: http://portal.mec.gov.br/seb/arquivos/pdf/blegais.pdf. Acesso em 28 de junho de 2020.
} 
As intermitências da filosofia no ensino básico: um quadro histórico-crítico

discutido nas instâncias institucionais, em meio à experiência do retorno formal dos saberes filosóficos e sociológicos à sala de aula, pelo formato adotado a partir da nova LDB. Ainda no contexto das mudanças implantadas gradativamente nos sistemas de ensino pelos Planos Curriculares, esta urgência foi fruto de discussões advindas de setores ligados à educação, associações profissionais, associações de pesquisa e instituições civis. São coetâneos às movimentações internacionais, no caso específico da Filosofia, objeto do encontro internacional que deu fruto à Declaração de Paris pela Filosofia ${ }^{6}$, de 1995, da qual a representação do Brasil é signatária. Já em meados de 2003, as primeiras audiências públicas institucionais sobre o tema tomaram por base as deliberações e as orientações do documento de Paris para a elaboração de um plano de trabalho em nível legislativo. Foi neste contexto que a Comissão de Educação, Cultura e Desporto da Câmara dos Deputados e as representações civis ligadas aos setores da educação e, particularmente, à pesquisa e ao ensino de Filosofia e de Sociologia iniciaram os debates sobre a reintegração das referidas disciplinas ao ensino básico.

Somente em junho de 2008, o presidente Luiz Inácio Lula da Silva sanciona a Lei n. 11.684/08, dando corpo às formulações acumuladas nos anos anteriores quanto à presença obrigatória das disciplinas Filosofia e Sociologia no currículo do ensino básico. Para tanto, o projeto de Lei propunha uma mudança no inciso IV do $1^{\circ}$ parágrafo do artigo 36 da LDB/96. Como sabemos, este dispositivo previa que o acesso aos conceitos e às práticas dos saberes da Filosofia e da Sociologia fossem ofertados aos estudantes de ensino fundamental o ensino médio "para o exercício da cidadania". Com a citada lei de 2008, o artigo passa a expressar exatamente a obrigatoriedade e a independência curricular para cada uma das duas disciplinas. Segundo o inciso referido acima: "serão incluídas a Filosofia e a Sociologia como disciplinas obrigatórias em todas as séries do ensino médio".

\section{0 quadro atual}

Nos anos seguintes à última retomada da disciplina de Filosofia no ensino básico, um conjunto de ações didáticas e de pesquisa em educação e em Filosofia, além de diversas práticas de interdisciplinaridade foram desenvolvidas nas Universidades e nas escolas do país, com o intuito de subsidiar a reinserção da disciplina em tela, rearranjando o campo de atuação e de pesquisa em Ensino de Filosofia. Programas de pesquisa a exemplo do PIBIC (Programa Institucional de Bolsa de Iniciação Científica) e do PIBID (Programa Institucional de Bolsas de Iniciação à Docência), além de Programas de pós-graduação de natureza profissional, ou até mesmo o PARFOR (Plano Nacional de Formação de Professores) no direcionamento da formação e da qualificação de professores aderiram a diversas ações desenvolvidas diretamente pelo MEC e, sobretudo, pelos Departamentos e Programas

\footnotetext{
${ }^{6}$ Declaração de Paris para a Filosofia: "Nós, participantes das jornadas internacionais de estudo "Filosofia e democracia no mundo", organizadas pela UNESCO, que ocorreram em Paris, nos dias 15 e 16 de fevereiro de 1995: Constatamos que os problemas de que trata a filosofia são os da vida e da existência dos homens considerados universalmente; Estimamos que a reflexão filosófica pode e deve contribuir para a compreensão e conduta dos afazeres humanos; Consideramos que a atividade filosófica, que não subtrai nenhuma ideia à livre discussão, que se esforça em precisar as definições exatas das noções utilizadas, em verificar a validade dos raciocínios, em examinar com atenção os argumentos dos outros, permite a cada um aprender a pensar por si mesmo; Sublinhamos que o ensino de filosofia favorece a abertura do espírito, a responsabilidade cívica, a compreensão e a tolerância entre os indivíduos e entre os grupos... (continua)" Disponível em http://www.ifil.org/unesco.htm. Acesso em 28 de junho de 2020.
} 
As intermitências da filosofia no ensino básico: um quadro histórico-crítico

de Pós-graduações, que ampliavam e amadureciam as exigências desta nova área de atuação docente, de acordo com as demandas surgidas.

Entretanto, em 2016, no contexto do golpe parlamentar que depôs a presidente Dilma Rousseff, o Governo Temer implementou medidas de contenção e diminuição de gastos públicos ${ }^{7}$, atingindo substancialmente os setores da Educação deste país, de modo que compreendeu a necessidade de interromper os avanços e as ampliações de algumas áreas de atuação docente, vislumbrando, assim, a descontinuidade da retomada da disciplina de Filosofia, na grade curricular obrigatória do ensino básico.

Para tentar impor e viabilizar a PEC 241/55 e para evitar a colisão legal explícita com outros dispositivos que ainda garantem direitos sociais, o governo, importando-se apenas com setores dominantes e de forma articulada com a mídia e segmentos políticos reacionários, editou a medida provisória n. 746/2016, promovendo alterações de fundo no ensino médio. Tal dispositivo teve seu conteúdo preservado na lei n. 13.415/2017, que efetivou a reforma, que pretende esvaziar o currículo escolar corroendo os conteúdos obrigatórios dessa etapa de ensino (LIMA \& MACIEL, 2018, p.20).

Ainda em 2016, a polêmica Medida Provisória n. 746, sancionada por Michel Temer e transformada em Lei para alteração na LDB (Lei n 13.415, de 16 de fevereiro de 2017) altera a Base Nacional Curricular Comum (BNCC), implantando o chamado "Novo Ensino Médio", o qual foi marcado pela carência de debates em torno de sua elaboração e implantação, levando a questionamentos de entidades civis da educação e à ação de membros do Ministério Público, no que tange a sua constitucionalidade. Fundamentalmente, a referida MP (Medida Provisória) acompanhou o golpe parlamentar, caracterizando-se como uma medida de caráter monista, ao prevalecer a decisão inconteste do MEC e do Executivo, que fizeram tábula rasa de décadas de discussão entre especialistas, entes públicos e sociedade civil acerca das políticas públicas para a educação básica.

Na configuração da MP de n. 746, transformada em Lei Ordinária, ficou entendido que, além da implantação do regime de tempo integral e do aumento da carga horária escolar, o ensino médio deveria ser dividido entre a disciplinas da Base Curricular Nacional Comum e cinco áreas específicas (Linguagens e suas Tecnologias; Ciência da Natureza e suas Tecnologias; Ciências Humanas e Sociais Aplicadas; Matemática e suas Tecnologias; e Formação Técnica e Profissional), dentre as quais, apenas Matemática, Língua Portuguesa e Língua inglesa possuem estatuto de disciplinas obrigatórias, restando às demais a alocação em um arranjo de componente curricular de caráter eletivo, podendo ser oferecidos em qualquer série do ensino médio. Esta orientação, carecendo de uma definição quanto à organização do ensino, criou uma atmosfera de fragilidade e de desvalorização em torno das

\footnotetext{
7 “Com um discurso moralista e oportunista contra a esquerda e com ampla base no Congresso Nacional, o governo golpista aprofundou o ajuste fiscal e prometeu asfixiar gastos primários, reformando suas bases jurídicas. 0 grau de institucionalidade e de amplitude dos direitos sociais - estes considerados caros pelas elites - passou a ser revisto, pois eram ações que ameaçavam a viabilidade da aritmética do superávit fiscal, para o qual o "gasto social" é menos importante que os interesses do capital parasitário. Assim, em um contexto inicial de alta da inflação e de desemprego (atingindo mais de 9,99\%, com valor situado entre 10 e 15\%) o Governo Temer, apesar de sua ilegitimidade e das recentes denúncias, vem logrando êxito em aprovar não apenas o esvaziamento dos direitos sociais, mas sobretudo em promover as reformas com o fito de conter os gastos sociais e garantir a governabilidade capaz de oferecer ao capital rentista a previsibilidade necessária ao aprofundamento do processo de acumulação" (LIMA \& MACIEL, 2018, p. 04).
} 
DIAS-SANTOS, A. R. (2020)

As intermitências da filosofia no ensino básico: um quadro histórico-crítico

disciplinas eletivas.

A BNCC estabelece para o ensino médio que as disciplinas de Sociologia, Filosofia, História e Geografia integram a área das "Ciências Humanas e Sociais Aplicadas". Contudo, restou sem previsão do legislador a disposição das disciplinas e demais definições curriculares, deixando às Secretarias Estaduais e aos Sistemas de Ensino a materialização desta divisão dentro de cada área. Na prática, este cenário gerou um grande vazio que, longe de configurar um espaço de liberdade na criação de currículos, significa uma grande incerteza sobre a presença de fato das referidas disciplinas. Isto porque a reforma do ensino traz consigo uma ampliação da carga-horária total (de 800 para 1.000 horas até uma meta de 1.400 horas ao ano) mas também estabelece uma divisão desigual entre as disciplinas integrantes da BNCC e as áreas específicas ${ }^{8}$. Esta divisão implica num máximo de 1.800 horas totais para a Base. Assim, a formação básica fica limitada a 600 horas anuais, aumentando a carga horária do ensino profissionalizante.

A Lei n. 13.415/2017 assim prevê em seu parágrafo $2^{\circ}$, artigo 26: “a Base Nacional Comum Curricular referente ao ensino médio incluirá obrigatoriamente estudos e práticas de educação física, arte, sociologia e filosofia" (Brasil, 2017). A olhos descuidados, uma leitura rápida do artigo 35-A da mesma lei pode levar ao entendimento de que sociologia e filosofia foram reinseridas como obrigatórias na BNCC. No entanto, há que se ponderar que não é exatamente isso que o texto da lei assegura, pois o que deve ser garantido são estudos e práticas, e não a inclusão obrigatória do componente curricular. Essa mudança desconsidera que filosofia e sociologia são campos de saberes, abrindo a possibilidade para que seus conteúdos sejam até mesmo tratados como temas transversais, diluídos em outras disciplinas da BNCC (LIMA \& MACIEL, 2018, p. 14).

Como atestam os autores, a oferta dos cincos eixos que compõem os itinerários específicos profissionalizantes deverá encontrar limitações que passam diretamente pelas questões orçamentárias, o que inclui a escassez de subsídios para o ensino e para a formação e manutenção do quadro docente necessário. A realidade econômica de Estados e de Municípios leva à previsão preocupante de que, em situações mais críticas, é possível que os estudantes tenham acesso apenas aos três componentes curriculares obrigatórios da BNCC e o eixo profissionalizante, visto que o texto da Lei n. 13.415/2017 estabelece que é facultada aos sistemas de ensino a definição dos eixos e seus itinerários, o que chegou a ser propagado como uma possibilidade de escolha para o aluno, ao que acrescentamos a contingência de que o sistema de ensino ao qual esteja vinculado ofereça todas as possibilidades formativas. Outro aspecto econômico da lei supracitada é a previsão de parcerias público-privadas para a implantação do Novo Ensino Médio e o surgimento da figura do Notório Saber ${ }^{9}$,

\footnotetext{
8 "A medida provisória não estabelece prazo e o seu enunciado não tem nenhum impacto imediato", apenas “caracteriza uma intenção já prevista no PNE". A ampliação do tempo integral no ensino médio foi mantida na Lei n. 13.415/2017, alterando, assim, a LDB, estipulando que em um prazo máximo de cinco anos, a partir da edição do PNE, todo o ensino médio deverá ter sua carga horária ampliada para 1.400 horas anuais, o que eleva a carga horária diária atual de quatro para sete horas” (LIMA, 2018, p. 11).

9 "De acordo com Frigotto (2016), tal postura desvaloriza ainda mais os "professores esfacelados em seus tempos" de trabalho, que muitas vezes são obrigados a estar "em duas ou três escolas em três turnos para comporem um salário que não lhes permite satisfazer suas necessidades básicas", que, não por acaso, é "um professorado que de forma crescente adoece". Ademais, a não exigência de licenciatura via notório saber representa uma tentativa do governo de resolver problemas estruturais do ensino médio, como a falta de professores em determinadas áreas e o custo que eles representam. Para Ramos (2016), isso é “da lógica da economicidade”. Segundo a autora, como é o sistema de ensino que vai decidir acerca da escolha dos itinerários formativos a serem ofertados, poderá
} 
um profissional que poderá ministrar conteúdos em áreas afins à sua formação ou à experiência no campo profissional.

\section{Conclusão}

No que tange à última reforma do ensino básico, verificamos que a disciplina de Filosofia retornou ao patamar da reforma de Diretrizes e Bases para a Educação de 1961, figurando como componente curricular sem obrigatoriedade de oferta pelos sistemas de ensino. Quanto ao estatuto geral das mudanças advindas com esta reforma, no "novo" ensino médio, os estudantes se deparam com uma situação similar às condições oferecidas pelas legislações educacionais anteriores à reforma de 1961, quando, até aquele momento o aluno tinha que escolher entre o ensino clássico, o normal, ou o científico. Hoje, esta divisão se encontra nas áreas específicas eletivas. 0 caso do Notório Saber é outro fator que garante o retrocesso no campo escolar, remetendo-se a condições anteriores à consolidação e à profissionalização das licenciaturas no país, sob o agravante de que a um Notório é permitido ensinar até mesmo em áreas afins ao seu "saber" ou experiência profissional comprovada.

As considerações sobre o ensino de Filosofia em tal cenário devem observar os prejuízos para sua consolidação como campo disciplinar. Prejuízos que passam pela elaboração didática de um processo de ensino e aprendizagem, com os acúmulos e perdas de experiências interrompidas ao sabor do "eterno retorno" da disciplina nas escolas. Tal situação fez com que se desenvolvesse um campo de investigação em ensino de Filosofia dedicado a pensar sua pertinência no ensino básico, ao lado do campo de pesquisa da Filosofia da Educação. A existência da disciplina nas escolas sempre esteve ligada a questões políticas e concepções humanistas frente à formação humana. Segundo Gallo (2007), todas as inserções da Filosofia no ensino se deram devido às condições oferecidas pelos seus saberes para o desenvolvimento da autonomia e da crítica. Em termos de legislações, encontramos uma tendência a instrumentalização do saber pela urgência das atitudes éticas e políticas com base na liberdade de ação, que se sobrepunham a outras habilidades e práticas teoréticas do campo, como a Estética e a Lógica. Reivindicando uma autonomia para o campo de pesquisa da Filosofia da Educação, diz o autor:

Não resta dúvida, porém, que a própria Filosofia forneceu as condições para ser tomada como fundamento da Educação, servindo ela mesma para "fundamentar" a noção da Filosofia e de outras áreas de saber. De certa forma, nos currículos de cursos de formação de professores, essa noção acaba gerando um conflito com a noção anterior, pois, ao se conceber a Filosofia como fundamento, ela é, por um lado, alocada, como já disse, nos momentos iniciais dos cursos; por outro, solicitase da Filosofia que exercite a "reflexão sobre" os fenômenos educacionais. (GALLO, 2007, p. 20).

Resta ainda o potencial crítico que a Filosofia carrega para dentro da escola, pensando a própria instituição escolar e a noção de disciplina. Há autores que defendem uma posição contrária à

então fazê-lo de acordo com aquela área em que possuir mais professores, desresponsabilizando-se, assim, com o problema da falta de docentes em outras áreas" (LIMA \& MACIEL, 2018, p. 19). 
As intermitências da filosofia no ensino básico: um quadro histórico-crítico

presença da Filosofia enquanto disciplina, alertando para um descompasso entre a filosofia e própria noção de disciplina: "Estes defendem que a inserção de mais uma disciplina escolar (...) seria sujeitála aos rituais e tratamentos pedagógicos que os estudantes costumam identificar, precisamente, como o oposto da crítica, do prazer, da autonomia etc" (Fávero, p.261, 2004). Contudo, defendemos não a noção de disciplina, mas a via da disciplina como acesso para os estudantes ao conhecimento filosófico. Neste artigo, vimos que, no contexto brasileiro, a dupla dos conhecimentos filosóficos e sociológicos só ganhou espaço nas escolas quando adentrou as salas de aula pela forma disciplinar. A filosofia é uma ferramenta à nossa disposição para o desenvolvimento do raciocínio crítico, na contramão do esvaziamento lógico, epistêmico e sensível do mundo contemporâneo, tão marcado pela "sensibilidade" virtual. A presença da Filosofia nas salas de aula também possui uma função de resgate de um sentido de ser próprio ao humano, histórico e, mais uma vez, sensível. Uma escola que despreza esta dimensão da formação humana está fadada à repetição dos mesmos automatismos que, por séculos, separam as ciências e seus saberes da sociedade.

\section{Quadro histórico}

- Lei n. 4.04/61: A filosofia deixa de ser ofertada como disciplina obrigatória no ensino básico do Brasil;

- Lei n. 5.692/71: A disciplina é retirada das grades curriculares eletivas;

- Lei n. 9.394/96 (LDB): Os saberes da filosofia são ofertados no ensino básico como componentes do eixo Ciências Humanas e suas Tecnologias, sob a ênfase da promoção do "ensino da ética e cidadania";

- DCN (CNE) /98 e PCNEM/ 99: A filosofia é sistematizada como saber incluído no campo curricular dos "Temas transversais" em ética e cidadania. Tal arranjo figurou como forma de garantir o cumprimento da LDB sem, no entanto, constituir o saber como disciplina autônoma.

> Junho de 2003: Audiência pública sobre a volta da filosofia e da sociologia na Comissão de Educação da Câmara dos Deputados. Discussão subsidiada pela Declaração de Paris para a Filosofia (UNESCO / 1995)

- Lei n. 11.684/08: Torna a filosofia e a sociologia disciplinas obrigatórias ofertadas no nos sistemas de ensino do país.

- MP n. 746/16: Proposta de alteração na LDB/96 que, dentre outras mudanças, retira a oferta obrigatória da disciplina de Filsofia da grade curricular.

- Lei n. 13.415/17: Institui o “Novo Ensino Médio”.

> No novo texto da LDB, o ensino médio resta compreendido pela BCCN (na qual apenas Matemática, Português e Inglês são disciplinas obrigatórias) e cinco áreas específicas eletivas. Uma delas, Ciências Humanas e Sociais Aplicadas abarca os saberes em Sociologia, Filosofia, História e Geografia, como estudos e práticas, sem previsão de um arranjo disciplinar obrigatório, independente e autônomo dentre estes saberes. Por fim, resta aos sistemas de ensino a oferta dos saberes que compõem cada eixo temático em disposições curriculares a serem estabelecidas de forma autônoma. 


\section{Referências}

BOURDIEU, P.; PASSERON, J. A reprodução. Elementos para uma teoria do sistema de ensino. Lisboa: 1970.

BRASIL. Lei n. 4.024, de 20 de dezembro de 1961. Diretrizes e Bases da Educação Nacional. DOU, Brasília, 27 dez. 1961. Disponível em: http://www.planalto.gov.br/ccivil_03/Leis/l4024.htm. Acesso em 28 de junho de 2020.

. Lei n. 5.692, de 11 de agosto de 1971. Diretrizes e Bases para o ensino de $1^{\circ}$ e $2^{\circ}$ graus e outras providências. DOU, Brasília, 12 ago. 1971. Disponível em: http://www.planalto.gov.br/ccivil_03/leis/L5692.htm. Acesso em 28 de junho de 2020.

. Lei n. 9.394, de 20 de dezembro de 1996. Estabelece as Diretrizes e Bases da Educação Nacional. Diário Oficial da União, Brasília, DF, 23 dez. 1996. Disponível em: http://www.planalto.gov.br/ccivil_03/leis/L9394.htm. Acesso em 28 de junho de 2020.

. Lei n. 11.684, de 2 de junho de 2008. Altera o art. 36 da lei n. 9.394, de 20 de dezembro de 1996. DOU, Brasília, DF, 3 jun. 2008. Disponível em: http://www.planalto.gov. br/ccivil_03/_ato20072010/2008/lei//11684.htm. Acesso em 28 de junho de 2020.

. Medida provisória n. 746, de 22 de setembro de 2016. Altera a lei n. 9.394, de 20 de dezembro de 1996, que estabelece as Diretrizes e Bases da Educação Nacional, e a lei n. 11.494 de 20 de junho 2007 e dá outras providências. Brasília, DF, 23 set. 2016. Disponível em: http://www.planalto. gov.br/ccivil_03/_ato2015-2018/2016/Mpv/mpv746.htm. Acesso em 28 de junho de 2020.

FÁVERO, A. et ali. O ensino da filosofia no Brasil: um mapa das condições atuais. Cadernos Cedes, Campinas, vol. 24, n. 64: 257-284, 2004.

FOUCAULT, M. Vigiar e punir. Vozes, São Paulo: 2007.

GALLO, S. Filosofia da Educação no Brasil do século XX: da crítica ao conceito. Eccos - Revista científica, vol. 09, n.02: 261-284, 2007.

JACOMELI, M. R. M. A lei 5.692 de 1971 e a presença dos preceitos liberais e Escolanovistas: Os Estudos Sociais e a formação da cidadania. Revista HISTEDBR On-line, n.39: 76-90, 2010.

LIMA, M. \& MACIEL, S. A reforma do Ensino Médio do governo Temer: corrosão do direito à educação no contexto de crise do capital no Brasil. Revista Brasileira de Educação, vol.23, 2018.

MARCUSE, H. Cultura e sociedade. Paz e Terra, São Paulo: 2006.

MOREIRA, A. et alii. Currículos, disciplinas escolares e culturas. Petrópolis, Vozes: 2018. 